\title{
Valuing deaths or years of life lost? Economic benefits of avoided mortality from early heat warning systems
}

\author{
Aline Chiabai ${ }^{1} \cdot$ Joseph V. Spadaro $^{1,2}$. \\ Marc B. Neumann ${ }^{1,3}$
}

Received: 16 January 2017 / Accepted: 14 December 2017 / Published online: 7 February 2018

(C) The Author(s) 2018. This article is an open access publication

\begin{abstract}
The study aims to explore the main drivers influencing the economic appraisal of heat warning systems by integrating epidemiological modelling and benefit-cost analysis. To shed insights on heat wave mortality valuation, we consider three valuation schemes: (i) a traditional one, where the value of a statistical life (VSL) is applied to both displaced and premature mortality; (ii) an intermediate one, with VSL applied for premature mortality and value of a life year (VOLY) for displaced mortality; and (iii) a conservative one, where both premature and displaced mortality are quantified in terms of loss of life expectancy, and then valued using the VOLY approach. When applying these three schemes to Madrid (Spain), we obtain a benefit-cost ratio varying from 12 to 3700. We find that the choice of the valuation scheme has the largest influence, whereas other parameters such as attributable risk, displaced mortality ratio, or the comprehensiveness and effectiveness of the heat warning system are less influential. The results raise the question of which is the most appropriate approach to value mortality in the context of heat waves, given that the lower bound estimate for the benefit-cost ratio (option iii using VOLY) is up to two orders of magnitude lower than the value based on the traditional VSL approach (option i). The choice of the valuation methodology has
\end{abstract}

The original version of this article was revised due to a retrospective Open Access order.

Aline Chiabai

aline.chiabai@bc3research.org

Joseph V. Spadaro

joseph.spadaro@aol.com

Marc B. Neumann

marc.neumann@bc3research.org

1 Basque Centre for Climate Change BC3, Building 1, 1st floor, Barrio Sarriena, s/n, 48940 Leioa, Bizkaia, Spain

2 SERC, Hillsborough, NJ 08844, USA

3 IKERBASQUE, Basque Foundation for Science, 48013 Bilbao, Bizkaia, Spain 
significant implications for public health authorities at the local and regional scale, which becomes highly relevant for locations where the application of the VOLY approach could lead to benefit-cost ratios significantly lower than 1 . We propose that specific metrics for premature and displaced VOLYs should be developed for the context of heat waves. Until such values are available, we suggest testing the economic viability of heat warning systems under the three proposed valuation schemes (i-iii) and using values for VOLY commonly applied in air pollution as the health end points are similar. Lastly, periodical reassessment of heat alert plans should be performed by public health authorities to monitor their long-term viability and cost-effectiveness.

Keywords Heat waves · Heat warning system - Economics of adaptation · benefit-cost ratio · Mortality valuation $\cdot \mathrm{VOLY} \cdot \mathrm{VSL}$

\section{Introduction}

Since the mid-twentieth century, several regions in the world (e.g., Europe, North America, East Asia, Australia, China) have been experiencing more frequent and more severe heat waves as an effect of global warming, with a corresponding increase in environmental thermal stresses, leading to hospital admissions and heat-related mortality (IPCC 2014). These impacts are especially prevalent in urban areas, affecting vulnerable groups such as the elderly, children, and individuals in poor health, especially those with pre-existing chronic conditions, people with disability or afflicted by obesity, and the urban poor. The frequency and intensity of extreme temperatures are expected to increase with the rise of global mean temperature, which will intensify the urban heat island effect. These impacts are further amplified by poor air quality, with consequent increased risks of heart diseases, strokes, and respiratory problems. Beniston (2004) concluded in his study that the 2003 European heat wave may very well represent an ordinary climatic event by the end of the century. This is confirmed by a recent analysis by Christidis et al. (2014), according to whom the probability of a heat wave event such as the one observed in 2003 in Europe has risen from 1 in a 1000 years to about 1 in a 100 years, with trends of frequency projected to further increase in the future. Also, exceptional heat waves that in the early 2000s were expected to occur twice a century are now expected to occur twice a decade (Christidis et al. 2014). Wang et al. (2015) observed over the worldwide land area that the projected increase in global mean temperature by the end of the century would also lead to a considerable geographical extension of "extremely hot" summers. Studies from around the world are beginning to recognize that the associated health impacts may be considerable (Im et al. 2017; Martinez Austria and Bandala 2016; Azhar et al. 2014; Benmarhnia et al. 2014; Vardoulakis et al. 2014; Anderson and Bell 2011).

As recognized by McGregor et al. (2015), heat waves rarely have received adequate attention in the past, as they lack the dramatic effects usually observed with tropical cyclones, flash floods, and other extreme weather events. Nevertheless, it is acknowledged that heat waves can produce severe impacts, with the already mentioned direct effects on health, as well as other indirect impacts such as increased water and electricity consumption, reduced agricultural yields, and threats to ecosystems and biodiversity (Seifert et al. 2015; Zuo et al. 2015). 
In this context, the implementation of heat warning systems (HWSs) can bring important health benefits in terms of avoided heat-related mortality and morbidity. Only few benefit estimates are available from the literature (Menne and Matthies 2009; ONERC 2009; Ebi et al. 2004; EPA 2015; Hunt et al. 2016). Additional economic evidence on adaptation benefits and costs of HWS is needed to set priorities at the regional, country, and city levels, in order to avoid unwanted economic losses to society due to maladaptation. The implementation of HWSs has become widespread in numerous countries around the world and is generally recognized as an important measure to address the health risks posed by heatwaves. A HWS aims at providing alerts to the health sector and the general population, as well as guidance on behavioral adjustment during dangerously hot episodes. It is part of a wider system including surveillance and emergency plans, as well as assistance services such as transport to emergency facilities and telecare.

A typical way in which warning alerts are launched is when a critical threshold temperature $\left(T_{\text {crit }}\right)$ is reached, above which heat-related health impacts are expected to increase significantly above a nominal baseline. $T_{\text {crit }}$ is also expected to change in time as a result of many factors, such as change in urban planning (e.g., green/blue areas, building insulation), population aging and general health status, technological and healthcare advances, and behavioral changes (Meusel et al. 2004; Abrahamson et al. 2008), besides physiological acclimatization (Aström et al. 2016). The choice of the critical temperature is crucial for an effective warning system, in order to support timely action to prevent health impacts, as well as avoid incorrect alarms which would bring economic losses for society, and decrease the receptiveness of population and health professionals (Rogers et al. 2010). Important requirements of HWS include, among others, the need to use local meteorological and demographic variables to set critical thresholds associated with real health impacts at the local scale, and to assess their cost-effectiveness, as recently stated in the WHO guidelines (McGregor et al. 2015).

Given that the monetized health benefits from avoided mortality are usually quite high in environmental regulation, it becomes important for policy making to consider the uncertainties related to mortality estimates and their associated costs. It is current practice to assess the averted mortality of a HWS by applying the value of a statistical life (VSL) indiscriminately to both displaced and premature deaths. This leads to a ratio of health benefits to operational costs which is typically on the order of a thousand, even when extensive and costly outreach actions are included in the HWS planning; consequently, a HWS is considered a very cost-effective adaptation response to urban heat stress under climate change. The published literature does not examine how alternative monetary valuations would influence the cost-effectiveness of a HWS compared to other parameters. With this study, we aim to explore the main drivers influencing the economic assessment of HWS, and specifically how the choice of the monetary valuation of mortality can affect the benefit-cost ratio. For this purpose, we develop a methodological framework to assess annual flows of benefits and costs of a HWS under different epidemiological, climate, and economic valuation assumptions. The analysis of the HWS is based on the prior assessment of the mortality impacts that rely on local epidemiological evidence specifying $T_{\text {crit }}$ and health risks attributable to heat waves. Our methodology is applied to the city of Madrid (Spain), for the period of 2020-2040, a time frame appropriate for policy making. Madrid presents a good case study because of its 
geographical location in the Mediterranean region, which is familiar with very hot summers and heat wave episodes (Colacino and Conte 1995).

\section{Assessment of heat-related mortality}

The consequences of extreme heat on health hinge on a wide range of interrelated factors, including sociodemographic characteristics, population health status, and association with other pollutants.

For this study, we used epidemiological studies from the literature for this specific site (Linares et al. 2014; Diaz et al. 2015). The empirical model estimates the heat wave threshold temperature $T_{\text {crit }}$, defined as the maximum air temperature when daily mortality (at the 95\% statistical significance level) exceeds the expected background daily mortality rate. For Madrid, $T_{\text {crit }}$ was found to be $34{ }^{\circ} \mathrm{C}$ for the reference period from 2001 and 2009 , and the temperature-mortality attributable risk $A R$, the proportion of daily deaths from natural causes attributable to heat exposure, is equal to $4.24 \%$ (95\% CI, 1.57-6.88) for each $1{ }^{\circ} \mathrm{C}$ above $T_{\text {crit }}$. The $A R$ is a mean summertime value age-weighted by the total exposed population, adjusted for covariates such as outdoor air particulate matter and ozone pollution, ambient noise, pollen concentration, and seasonal influenza incidence rate.

The expected annual mortality burden $M_{t}$ in year $t$ under alternative socioclimatic scenarios is calculated as:

$$
M_{t}=\mu_{t} \cdot A R \cdot\left(T_{\max }-T_{\text {crit }}\right)_{t} \cdot \operatorname{Ndays}_{t}=\mu_{t} \cdot A R \cdot \Delta \operatorname{Temp}_{t} \cdot \operatorname{Ndays}_{t}
$$

Time-based data on daily mortality rate from natural causes $\mu_{t}$, mean daily excess temperature, $\Delta$ Temp $_{t}=\left(T_{\max }-T_{\text {crit }}\right)_{t}$, and number of heat wave days $N$ days $s_{t}$ are calculated for summer days when the daily maximum temperature, $T_{\max }$, exceeds the heat wave threshold temperature $T_{\text {crit }}$ Here, summertime covers the time period from 1 June to 30 September. $A R$ is kept constant in Eq. 1. The expected total mortality $T M$ between years 2020 and 2040 is calculated as follows:

$$
T M=\sum_{t} M_{t}=\sum_{t} \mu_{t} \cdot A R \cdot \Delta \operatorname{Temp}_{t} \cdot \text { Ndays }_{t}
$$

The heat anomaly is distinguished between displaced and advanced (premature) deaths. Mortality displacement refers to acute deaths that occur during or immediately after a heat episode and concern people at the end of their lives who would have died regardless of heat exposure. The increase in mortality rate, which is then accompanied by a short-term anomalous reduction of deaths in the population, is known as "harvesting" (Hajat et al. 2005; Saha et al. 2014; Armstrong et al. 2014).

Premature mortality, on the other hand, refers to heat-related excess deaths in otherwise healthy individuals, who die earlier because of heat exposure. This affects different segments of the population disproportionally, especially the elderly (living alone or socially isolated), but also other groups such as infants and young children, manual workers, and people who engage in strenuous outdoor activities during hot weather. The loss of life per premature death depends on the expected remaining life of an individual at death and health status and may range from several months to the remaining life expectancy at age of death. The majority of people who succumb to heat stress are primarily aged 75 and over (Linares et al. 2014). 
Taking into consideration the difference between displaced and premature mortality, we rewrite Eq. 1 as follows:

$$
\begin{gathered}
D M_{t}=\mu_{t} \cdot A R \cdot \Delta \text { Temp }_{t} \cdot \text { Ndays }_{t} \cdot D M R \\
P M_{t}=\mu_{t} \cdot A R \cdot \Delta \text { Temp }_{t} \cdot \text { Ndays }_{t} \cdot(1-D M R)
\end{gathered}
$$

$D M_{t}$ are the expected annual displaced deaths in year $t$, and $P M_{t}$ the expected annual premature deaths. $D M R$ is the displaced mortality ratio, the share of deaths in $M_{t}$ due to displaced mortality.

An alternative indicator of mortality impact is the number of years of life lost YLL, which considers the remaining years of life expectancy at the time of death (OECD 2001; WHO 2013; Gardner and Sanborn 1990; McDonnel et al. 1998). The impact of heat waves on the annual years of life lost due to displaced $D Y L L_{t}$ and premature $P Y L L_{t}$ mortality is calculated as follows:

$$
\begin{gathered}
D Y L L_{t}=\mu_{t} \cdot A R \cdot \Delta \operatorname{Temp}_{t} \cdot \operatorname{Ndays}_{t} \cdot D M R \cdot \gamma_{d} \\
\text { PYLL }_{t}=\mu_{t} \cdot A R \cdot \Delta \operatorname{Temp}_{t} \cdot \text { Ndays }_{t} \cdot(1-D M R) \cdot \gamma_{p}
\end{gathered}
$$

$\gamma_{d}$ and $\gamma_{p}$ represent, respectively, the mean loss of life per displaced and premature deaths.

\section{Model assumptions}

\subsection{Socioclimatic projections}

Heat-related mortality and economic benefits and costs of heat alert systems are projected assuming different scenarios that reflect uncertainty about climatic and socioeconomic development (Gosling et al. 2009; Dessai 2003). For daily maximum temperature $T_{\max }$, we assume two climatic projections between 2020 and 2040 based on Representative Concentration Pathway (RCP4.5 and RCP8.5) scenarios presented in IPCC's Fifth Assessment Report AR5 (van Vuuren et al. 2014).

RCP8.5 is a high $\mathrm{CO}_{2}$ emissions scenario, driven by a strong reliance on fossil fuels and strong population growth. RCP4.5, instead, is an intermediate emissions scenario characterized by ambitious emission reductions consistent with strict climate policies. Projections of $T_{\max }$ for each scenario are taken from Scoccimarro and Gualdi (2014) who downscaled Coupled Models Intercomparison Project (CMIP5) simulations with the Rossby Center Atmosphere (RCA4) regional model.

The RCP climate scenarios are coupled with alternative global socioeconomic projections developed within the Shared Socio-economic Pathways (SSPs) based on evolution of economic, demographic, social, technological, environmental, and governance assumptions. In this study, RCP4.5 is coupled with SSP2, representative of the middle of the road expectations with significant heterogeneities within and among countries. On the other hand, RCP8.5 is combined with SSP5, characterized by high and rapid economic growth, strong population growth and consumption, and lack of global environmental action (O'Neill et al. 2013, 2015). 


\subsection{Mortality parameters}

The main assumptions and inputs for mortality calculations in this study are summarized in Table 1 . The heat attributable risk $A R$, displaced mortality ratio $D M R$, and mean loss of life expectancy are kept constant, whereas the remaining variables are changing over time.

For the period 2001-2009, the mortality in Madrid on heat wave days $\left(T_{\max }>\right.$ $T_{\text {crit }}=34^{\circ} \mathrm{C}$ ) was 57.5 deaths per day (Linares et al. 2014). The daily mortality rate $\mu_{t}$ is an age-weighted projection over time using Spanish Statistical Office (INE 2014) demographic assumptions for the city of Madrid up to year 2040. The empirical evidence on mortality displacement is still limited, and results across studies are sometimes inconsistent. Thus, we select an upper and lower bound estimate using results from (Saha et al. 2014) who analyzed mortality displacement in seven US cities over the period between 1980 and 2009.

The loss of life attributed to a displaced death $\gamma_{d}$ is assumed equal to 16 days, the mean of the interval ranging from a few days to about 1 month, but could be more depending on local conditions (Hajat et al. 2005; Saha et al. 2014). For premature deaths, we assume the loss of life $\gamma_{p}$ ranges between several months and the expected remaining life years at the age of death. The lower bound of this range is inferred on the basis of years of life lost for an acute death from air pollution (Bickel and Friedrich 2005), since intense heat and air pollution adversely affect the human circulatory and respiratory systems. Based on demographic projections for Madrid during the time period 2020-2040, we estimate a loss of life of around 4.7 years per premature death. This number represents a weighted mean considering future changes in life expectancy, population age distribution as determined from life table projections by the Spanish Statistical Office (INE 2014), and heat deaths by age group as determined for Madrid by (Linares et al. 2014). $\gamma_{d}$ and $\gamma_{p}$ are kept constant over time.

Table 1 Parameters for calculating heat-related mortality

\begin{tabular}{|c|c|c|}
\hline Parameter & Description & Value \\
\hline $\operatorname{Tmax}_{t}$ & $\begin{array}{l}\text { Time series of daily maximum } \\
\text { temperatures } 2020-2040\left({ }^{\circ} \mathrm{C}\right)\end{array}$ & $\begin{array}{l}\text { Time series for each RCP climate scenario } \\
\text { (Scoccimarro and Gualdi 2014) }\end{array}$ \\
\hline$\mu_{t}$ & $\begin{array}{l}\text { Daily mortality from natural causes } \\
\text { during heatwaves }\end{array}$ & $\begin{array}{l}\text { Projected over time using demographic data } \\
\text { (INE 2014) }\end{array}$ \\
\hline$A R$ & $\begin{array}{l}\text { Heat attributable mortality as } \% \text { of } \\
\text { daily deaths per } 1{ }^{\circ} \mathrm{C} \text { above } T_{\text {crit }}\end{array}$ & $\begin{array}{l}4.24 \% \text { per }{ }^{\circ} \mathrm{C}(95 \% \mathrm{CI}, 1.57-6.88 \%) \\
\text { (Linares et al. } 2014) \\
\text { Maintained constant over time }\end{array}$ \\
\hline$D M R$ & $\begin{array}{l}\text { Displaced mortality ratio as \% total } \\
\text { heat-related deaths }\end{array}$ & $\begin{array}{l}\text { Lower bound }=35 \% \text {; upper bound }=75 \% \\
\text { (Saha et al. 2014) } \\
\text { Maintained constant over time }\end{array}$ \\
\hline$\gamma$ & $\begin{array}{l}\text { Loss of life expectancy } \\
\quad \text { (years of life lost per deaths) }\end{array}$ & $\begin{array}{l}\gamma_{d}=16 \text { days (displaced death) } \\
\gamma_{p}=4.7 \text { years (premature death) } \\
\text { (own assumptions) } \\
\text { Maintained constant over time }\end{array}$ \\
\hline
\end{tabular}




\section{HWS evaluation: methodological steps for benefit and cost assessment}

In this section, we present the methodological framework to assess the annual flows of benefits and costs of a HWS, combining information on $T_{\text {crit }}$ and projected maximum daily temperatures $\operatorname{Tmax}_{t}$ over the period 2020-2040. We apply the framework to the city of Madrid.

\subsection{HWS benefits from avoided mortality}

The assessment is conducted as follows: (a) estimation of the preventable mortality, (b) choice of the monetary metric and adjustment of economic values from literature to study site, and (c) projections of flows of benefits over time.

\subsubsection{Estimation of preventable mortality}

The economic benefits of heat alert systems can be valued on the basis of potentially avoided mortality impacts $(A M)$, in terms of the percentage of preventable deaths or years of life lost, given the expected effectiveness $(E)$ of the HWS:

$$
A M_{t}=M_{t} \cdot E
$$

Given the absence of studies evaluating the effectiveness of HWS specifically for Madrid, we refer to Fouillet et al. (2008) which is one of the most comprehensive studies in this respect in Europe. They evaluated the effectiveness of the alert system and prevention plan adopted in France in 2006 by comparing observed excess deaths with those that would have been expected to occur in the absence of preventive measures. The evaluated plan comprises a wide set of measures in line with those typically introduced in Europe and North America (McGregor et al. 2015), ranging from the setup of a warning system to real-time surveillance of health data, and emergency plans for vulnerable people with visits and care offer. Following the Fouillet et al. (2008) analysis, we assume $E$ varies between 60 and $78 \%$, with a central value of $65 \%$. The range is in line with the findings of Ebi et al. (2004) and Benmarhnia et al. (2016) for North American cities.

\subsubsection{Choice of monetary metric to value mortality}

For mortality valuation, two approaches have been used in the literature and by governmental agencies (European Commission 1999): the VSL and the VOLY. Both values provide a monetary metric to estimate the benefits of measures that deliver a risk reduction on health (OECD 2001). The VSL is based on the individual willingness to pay (WTP) for small reductions in the risk of dying. The VOLY is derived from the willingness to pay for increasing life expectancy by one additional year.

Although decision making in public health continuously involves comparing incremental costs with expected benefits, the monetization of mortality has been criticized in the literature on the basis that human life is inestimable and cannot be priced (Ackerman and Heinzerling 2004; Patokos 2010). However, even when explicit values are not provided, mortality risk reductions will receive an implicit valuation through the decision to either implement or not to implement a particular policy. Using unambiguous values of VSL or VOLY is therefore preferred to support more transparent and consistent decision-making process (OECD 2011). 
In the context of air pollution, OECD $(2008,2011)$ recommends using VSL as a general rule. European Commission (1999), the Clean Air for Europe (CAFE) program (Hurley et al. 2005; Watkiss et al. 2005), and the APHEKOM project (Chanel 2011) suggest VOLY as the preferred approach for short-term effects on mortality from air pollution. Hurley et al. (2005) have argued that assigning a full statistical life for short-term exposure to air pollution with consequential minor changes in life expectancy might be misleading.

The VSL has been commonly used to assess the mortality impact of heat waves in previous studies leading to very high benefits of heat warning systems (Ebi et al. 2004; EPA 2015). However, the same debate on air pollution applies in the context of heat waves, where existent studies have estimated a few days to about 1-month change in life expectancy for displaced mortality (Saha et al. 2014; Hajat et al. 2005). So, in the context of displaced deaths, heat stress is a contributing cause of death, but not the main underlying mortality risk factor. Therefore, assigning a full statistical life for such a short reduction of life expectancy might exaggerate the economic impact or conversely exaggerate the benefits of an averted heat death. To shed further insights on heat wave mortality valuation, we propose to compare three approaches (Table 2). Option 1 is the traditional approach where VSL is applied to both displaced and premature mortality. Option 2 is an intermediate view, in which we use VSL for premature deaths, and VOLY for displaced mortality, considering the appropriate loss of life. Option 3 is a conservative approach where both premature and displaced deaths are calculated in terms of loss of life expectancy and valued as VOLYs.

Table 3 summarizes the mortality costs selected for this study. For VSL, we rely on the global meta-analysis of stated preference studies conducted by Lindheim et al. (2011) in the context of environmental, health, and transport policies. For EU27, the recommended VSL is 3.6 million dollars (at 2005 prices).

For displaced mortality, we have taken the air pollution VOLY estimated by Chilton et al. (2004) as a proxy for "displaced VOLY" in the heat wave context, given the lack of specific valuation studies. Using mortality valuation estimates from air pollution context can be a reasonable first approximation given that health outcomes (cardiovascular and respiratory diseases) are similar across the two risk factors (air pollution and heat waves). The estimate by Chilton et al. (2004) was determined using a WTP survey conducted in the UK to estimate the monetary equivalent of a small change in life expectancy under the context of short-term mortality associated with air pollution exposure. More specifically, this corresponds to a gain of 1 month in life expectancy for someone currently in poor health. The study of Chilton et al. (2004) revealed that people attributed a lower value to a gain in life expectancy when faced with poor health compared to the preference of a healthy individual. For premature deaths, as a proxy for "premature VOLY" in the heat wave context, we use the value of de Ayala and Spadaro (2014), who recommend an estimate for the EU-27 considering the available literature on long-term mortality in the context of air pollution.

Table 2 Monetary approaches used for mortality valuation

\begin{tabular}{llll}
\hline Mortality indicator & \multicolumn{2}{l}{ Monetary approach } & \\
\cline { 2 - 4 } & Option 1 & Option 2 & Option 3 \\
\hline Premature & VSL & VSL & Premature VOLY \\
Displaced & VSL & Displaced VOLY & Displaced VOLY \\
\hline
\end{tabular}


Table 3 Valuation of heat-related mortality in year 2020 (base costs €2013)

\begin{tabular}{|c|c|c|c|c|}
\hline Mortality indicator & $\begin{array}{l}\text { Monetary } \\
\text { approach }\end{array}$ & Reference value & $\begin{array}{l}\text { Adjusted } \\
\text { value } \\
\text { for Spain }\end{array}$ & $\begin{array}{l}\text { Source for } \\
\text { reference value }\end{array}$ \\
\hline $\begin{array}{l}\text { Premature deaths } \\
\quad \text { (loss of statistical life) }\end{array}$ & VSL & $\begin{array}{l}3.6 \text { million } \$ 2005 \\
\quad(\text { EU-27) }\end{array}$ & 4.1 million & OECD (2011) \\
\hline $\begin{array}{l}\text { Premature deaths (loss of } 1 \text { year of } \\
\text { life expectancy in normal health) }\end{array}$ & $\begin{array}{l}\text { Premature } \\
\text { VOLY }\end{array}$ & $\begin{array}{l}90,000 € 2013 \\
\quad(\mathrm{EU}-27)\end{array}$ & 109,000 & $\begin{array}{l}\text { de Ayala and } \\
\text { Spadaro (2014) }\end{array}$ \\
\hline $\begin{array}{l}\text { Displaced deaths (loss of } 1 \text { month of } \\
\text { life expectancy in poor health) }\end{array}$ & $\begin{array}{l}\text { Displaced } \\
\text { VOLY }\end{array}$ & $7280 £ 2004$ (UK) & 10,300 & $\begin{array}{l}\text { Chilton et al. } \\
\text { (2004) }\end{array}$ \\
\hline
\end{tabular}

Income elasticity is 0.8 for adjustment over space and 1 for adjustment over time (OECD 2011)

The reference values obtained from the literature (Table 3) have been adjusted to Euro 2013 accounting for income differences, as well as for changes in the cost of living over time. For this, we follow the recommendations of OECD (2011) and economic indicators from the World Bank (http://data.worldbank.org/indicator): (i) conversion to the national currency using the Purchasing Power Parity (PPP) adjusted exchange rate, (ii) adjustment to current prices using the Consumer Price Index (CPI), and (iii) adjustment for variation of real income in time and space using the PPP-adjusted gross domestic product (GDP) per capita. The reference values have been further adjusted for GDP per capita growth from the baseline year 2013 to year 2020.

\subsubsection{Projections of benefits over time}

As the mortality benefits occur over time, economic values have been adjusted to reflect the real purchase power of the population in future years according to SSP2 and SSP5 projections. The total benefits are then obtained by summing the annual flow of benefits:

$$
T B=\sum_{t} \frac{A M_{t} \cdot V_{t}}{(1+d)^{t}}
$$

$T B$ is the present value of the total benefits for the chosen time period 2020 2040 ( $t=0$ to 20); $A M_{t}$ are the preventable deaths or $Y L L$ in each year $t ; V_{t}=\left[V_{t-}\right.$ $\left.1 \cdot\left(1+\beta g_{g d p}\right)\right]$ is the VSL or VOLY adjusted for variation of real income in time, where $V_{0}$ is the value estimated for Spain in Table 3 for $t=0 . g_{g d p}$ is the growth rate of the PPP-adjusted GDP per capita for Spain according to the SSPs scenarios, $\beta=1$ is the income elasticity over time (OECD 2011), and $d$ is the discount rate. In the case of HWS, where costs and benefits are occurring at the same time, the impact of discounting on the benefit-cost ratio is not significant, so that we take $d=0$.

\subsection{HWS operational costs}

The assessment is conducted as follows: (a) type of actions included, (b) choice of the monetary values, and (c) projections of flows of costs over time. 


\subsubsection{Type of actions}

A heat warning system must provide advice on protective behavior to the general public, as well as to targeted vulnerable groups (the elderly, children, people with serious chronic illnesses and mobility problems, low-income groups, outdoor workers) (PHE 2013). It is active during a specified operational timeframe which depends on the period when heat-related health burdens are expected to increase anomalously. These systems use information on weather forecasting and threshold temperatures to release watch alerts and warning messages. Specific operational conditions and actions foreseen to reduce health risks vary according to the geographical location. A HWS is usually part of a wider Heat-Health Action Plan (HHAP) (McGregor et al. 2015), which comprises a number of actions at the community level, when the pre-identified alert threshold is reached. These are public health actions which, in Europe and the USA, generally include media announcements to the general public that suggest behavioral recommendations, a bulletin or web page directed to professionals or for the overall population, leaflets for home care managers, dedicated telephone heat lines, and alerts going out to hospital emergency services and health centers, among others (McGregor et al. 2015). Following the 2003 heat wave, the Health Department in Madrid has put in place a warning system whose actions are aligned with those of other countries in Europe and the USA (Comunidad de Madrid 2015).

\subsubsection{Choice of monetary values}

The cost assessment within a benefit-cost analysis of any intervention in public health usually involves a number of steps, including the identification of specific actions, the categorization of costs, and the quantification of personnel and time required as well as projections and discounting (Hutton and Rehfuess 2006). In practical terms, difficulties arise when estimating the costs of HWS in specific urban contexts due to the lack of a specific dedicated budget for planning, limited accessibility of quantitative information on personnel, and time dedication per type of action from implementing agencies, as well as lack of studies providing a transparent and comprehensive analysis of resource costs. Given these limitations, a basic procedure has been followed for the Madrid case study that relies on information from Ebi et al. (2004). We assume a lower bound estimate of direct costs per day, referring to basic activities such as the additional labor required to maintain a heat line and emergency medical services, and an upper bound for a wider set of actions, which additionally include dissemination campaigns, media announcements, and alerts to nursing homes and other facilities that provide extra care to vulnerable people through community outreach programs. The estimates in Table 4 are adjusted to year 2013 for national currency, changes in real income per capita (in time and space),

Table 4 Projected operational costs of HWS in year 2020 (base costs €2013)

Actions

Cost per heatwave day

Basic interventions

7800

Basic interventions + supplementary actions

14,000

Adapted from Ebi et al. (2004) 
and population size at risk, and further corrected for GDP per capita and population growth from the baseline year 2013 to year 2020 .

\subsubsection{Projections of costs over time}

Annual costs are projected to 2040 using PPP-adjusted GDP per capita to reflect increased labor wages over time in future scenarios (SSP2 and SSP5), population growth, and taking into account the number of days in which the HWS is activated, when the maximum daily temperature is above $T_{\text {crit }}$. Income elasticity is applied in the same way as for the valuation of benefits in Section 4.1. Annual costs are summed to obtain the total cost:

$$
T C=\sum_{t} \frac{\operatorname{Ndays}_{t} \cdot D C_{t}}{(1+d)^{t}}
$$

$T C$ is the present value of the yearly flow of costs for the period 2020-2040 with $t=0$ to 20 years; Ndays $s_{t}$ is the number of days in which the maximum daily temperature is above $T_{\text {crit }}$ in year $t$; the operational costs per heat wave day are $D C_{t}=\left[D C_{t-1} \cdot\left(1+\beta g_{\mathrm{gdp}}+g_{\mathrm{pop}}\right)\right]$ and $D C_{0}$ are the costs reported in Table 4 for $t=0 . g_{g d p}$ and $g_{p o p}$ are, respectively, the growth rate of the PPP-adjusted GDP per capita and the growth rate of the population for Spain according to the SSPs scenarios, $\beta=1$ is the income elasticity over time, and $d$ the discount rate (where we have chosen $d=0$ ).

\section{Results and discussion}

\subsection{Mortality impacts in the absence of HWS}

Total mortality for Madrid City TM is computed following Eq. 2. The decomposition into premature and displaced deaths as well as the life years lost $(Y L L)$ is presented in Table 5. Note that the influence of the RCP scenario is less pronounced than the effect of $A R$ and $D M R$ on mortality variability in the period of reference. Further, the years of life lost due to displaced mortality are at most a few percent of the total loss of life (0.5-3\%), although displaced mortality accounts for $35-75 \%$ of deaths. This raises an important methodological question concerning which is the most appropriate metric to estimate mortality displacement.

\subsection{Comparison of benefits vs. costs of HWS under RCP8.5}

We present the results for RCP8.5, which is a business as usual scenario. The cumulative health benefits over the period 2020-2040 ranges between 0.11 and 18.7 billion $€$. This range reflects different choices of the input parameters and their lower and upper bounds. For, instance, the lower bound estimates correspond to the lowest $A R$ and HWS effectiveness, along with DMR $=75 \%$ and VOLY valuation for mortality (option 3). Conversely, the highest $A R$ and HWS effectiveness coupled with VSL valuation (option 1) gives the upper bound.

Operational costs are determined by the number of days when the HWS is active and upon the comprehensiveness of the intervention plan. The range for the 20 -year time span varies from 5.1 to 9.2 million $€$.

Comparison of health benefits and operational costs reveals that the benefit-cost ratio (BCR) (Table 6) might vary from a lower bound central estimate of 42 (option 3 ) and an upper 


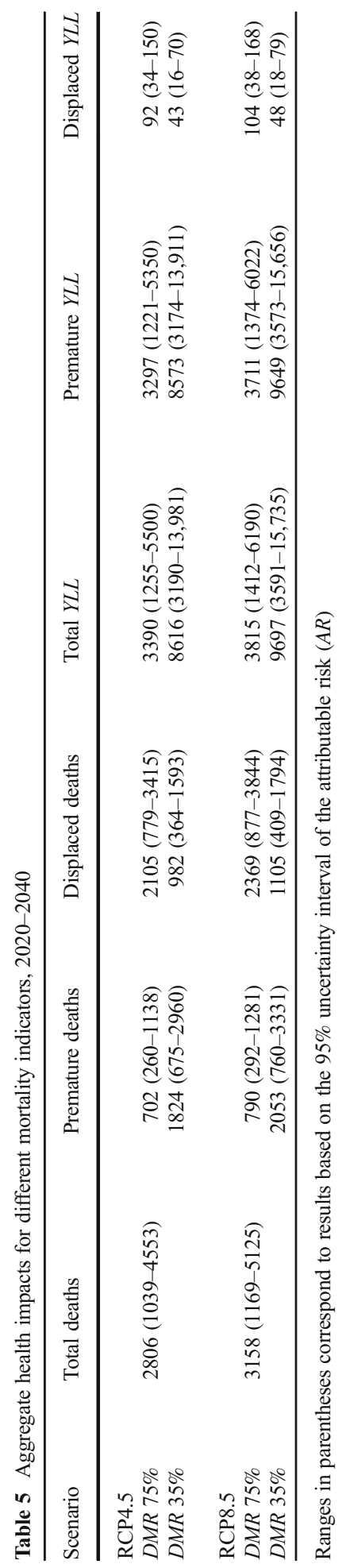


bound central estimate of 1350 (option 1) for the three valuation schemes considered here. The ranges around the central estimates reflect different combinations of low and high input assumptions, rather than a formal confidence interval. The upper bound under Option 1 (BCR $=3700$ ) is consistent with the estimates published previously by Ebi et al. (2004) and Hunt et al. (2016), whereas the lower bound under Option $3(\mathrm{BCR}=12)$ is two orders of magnitude smaller, and could, therefore, be interpreted as a conservative estimate of the potential impact of a HWS on saving lives.

In Table 7, we present the effect of the different input parameters on the benefit-cost ratio. The principal key driver turns out to be the mortality valuation approach, which can affect the ratio by a factor up to 32 if we compare the most conservative approach for valuation (option 3) with the traditional one (option 1). Less influential drivers for the benefit-cost ratio include the attributable risk $A R$ and the displaced mortality ratio $D M R$. More epidemiological research in view of defining critical values for $D M R$ based on localized data could reduce the impact of this parameter.

Finally, the choice of the socioclimatic scenario has a negligible influence on the benefitcost ratio as both benefits and costs are proportional to the number of heat waves days (Ndays) and the mean excess temperature $\left(T_{\max }-T_{\text {crit }}\right)$ is not very different between RCP/SSP combinations in the time period of reference (Scoccimarro and Gualdi 2014). A wider gap in the results is expected over the latter part of the twenty-first century as higher temperatures are projected under RCP8.5 compared to those under RCP4.5.

These results raise an interesting research question: Which mortality valuation approach (VSL or VOLY) is the most appropriate for projecting the health benefits of a HWS?

The answer to this question may have potential consequences for adaptation policy at the local and regional scale, as the choice of the mortality values may affect the benefit-cost ratio significantly depending on the geographical region under analysis, with economic benefits not outweighing the costs in some areas. Applying our methodological approach to the study of Hunt et al. (2016), we would expect to find a lower bound BCR $<1$ for London (Northwest Europe) and a lower bound BCR on the order of one for Prague, Czech Republic (Eastern Europe).

\section{Caveats and further research}

\subsection{Uncertainty and time dependency}

We have accounted for uncertainty in various physical and economic factors by either considering different levels or ranges for their values. This could be further refined by eliciting distribution functions for all model parameters in view of a full probabilistic analysis.

Table 6 Benefit- cost ratio under different monetary approaches for mortality valuation under RCP8.5

\begin{tabular}{lllr}
\hline Benefit-cost ratio & \multicolumn{2}{l}{ Monetary approach } & \\
\cline { 2 - 4 } & Option 1 VSL/VSL & Option 2 VOLY/VSL & Option 3 VOLY/VOLY \\
\hline$D M R 75 \%$ & $1350(360-3700)$ & $340(90-900)$ & $42(12-120)$ \\
$D M R 35 \%$ & & $870(230-2400)$ & $110(30-300)$ \\
\hline
\end{tabular}

Value ranges attributable to the $A R$, comprehensiveness of the plan in terms of costs, and its effectiveness 
Table 7 Effects of input parameters on benefit-cost ratio

\begin{tabular}{lc}
\hline Parameters & Variation factor \\
\hline Monetary valuation & 32 \\
Attributable risk & 4.4 \\
Displaced mortality & 2.6 \\
Comprehensiveness of plan & 1.8 \\
Effectiveness of HWS & 1.3 \\
RCPs/SSPs & 1.1 \\
\hline
\end{tabular}

Most of the heat-related mortality studies assume that the current threshold temperature and/or the temperature-mortality association will remain unchanged in the future (Baccini et al. 2011; EPA 2015). Although this assumption may be reasonable over the short term (in fact, in our own analysis for 2020-2040, we assume constant $T_{\text {crit }}$ and $A R$ ), future long-term studies should explore the possibility of time-varying threshold temperature and attributable risk due to potential techno-socioeconomic acclimatization processes. The variability of these parameters has global implications as their future evolution depends very much on prevailing meteorological conditions and population health trends, attributes that clearly have a geographical dimension.

\subsection{Morbidity benefits}

We should note that the health benefits are underestimated due to the fact that morbidity has not been included in the current analysis. Linares and Díaz (2008) have estimated morbidity effects directly linked to heat stress in Madrid, specifically related to hospital admissions from respiratory and cardiovascular causes. More recently, they extended their analysis of the impact of temperature to include mental health (Linares et al. 2016). In terms of economic valuation, however, morbidity benefits are relatively small compared to those of mortality. Even the loss of 1 month for a displaced death $(10,300 €)$ is around three times the cost of a hospital stay. In the case of air pollution, as a proxy example, hospitalization costs are much less than $1 \%$ of the mortality burden (Bickel and Friedrich 2005). Therefore, addition of heat-related illnesses would not change in a significant way the conclusion regarding the cost-effectiveness of a HWS.

\subsection{HWS costs}

HWS operational costs have been estimated following simplified assumptions. More studies are required for better categorization of costs and human resources to establish, maintain, and operate a HWS. A HWS is part of the public health decision-making process, and any assessment of its effectiveness and associated costs should be carried out in collaboration with the public health sector (Roger et al. 2010).

\subsection{Need for local studies}

The economic analysis by Hunt et al. (2016) has demonstrated that local considerations do matter, and depending on the input data, they found significant variability in the results across the three European cities considered in that study. For the case of London, UK, for example, under certain combinations of assumptions, a HWS was found not to 
be cost-effective under climate change, meaning that resource costs exceeded the expected health benefits of the intervention. Thus, local evidence from one particular study, in general, can neither be directly transferred to other locations, nor readily upscaled to the regional or global level.

\section{Conclusions and recommendations}

Heat waves are expected to intensify in the future as a consequence of climate change, implying an increase of heat-related mortality, especially among vulnerable groups in urban settings. As HWSs represent an essential adaptation strategy, it is important to assess their economic viability.

This paper presents a systematic framework for valuing costs and benefits of HWSs using a bottom-up approach. We find that among the many parameters that influence the benefit-cost ratio (BCR) of a HWS, the choice on how to conduct the mortality valuation (VSL vs VOLY) is the key driver, contributing to an order of magnitude change in BCR. Coupled with uncertainties in epidemiological data, and comprehensiveness of the alert plan, the BCR between the two approaches can vary by up to two orders of magnitude. The analysis opens the debate of which approach is best suited to project the health benefits of a HWS, given that the benefits may not exceed the costs when applying the VOLY approach at a particular location.

This has potentially significant consequences at the global scale, suggesting that there is no one-size-fits-all solution. Local specificity prevents any generalization given that local climate, demographic, and epidemiological conditions are highly inhomogeneous within and across countries. Therefore, adaptation efforts to establish HWSs need to be developed locally and properly reflect the nexus between hazards, population exposure, and socioeconomic vulnerabilities.

The most adequate economic approaches should be used to value HWSs, including the development of specific estimates for displaced and premature VOLYs suitable for heat mortality assessment, in order to avoid inefficient and maladaptation strategies. Until such values are available, our recommendation is to apply the three suggested valuation approaches to test that the BCR is greater than unity and use VOLY values borrowed from air pollution context given that the health outcomes are similar.

Finally, for a HWS to remain a viable and cost-effective option for heat adaptation, it is important that public health authorities periodically review their economic viability and effectiveness. Reassessment every 10 years could be recommended as this might represent an appropriate time scale to observe epidemiological changes in health risks in response to socioclimatic-economic trends, technological and medical advances, health system, and community-coordinated actions against excessive temperatures, as well as individual physiological acclimatization.

Acknowledgments This study is part of the project BASE (Bottom-up Climate Adaptation Strategies for a Sustainable Europe) funded by the European Union's Seventh Framework Programme for research, technological development, and demonstration under Grant Agreement No. 308337. Marc B. Neumann also acknowledges financial support from the Ramón y Cajal Research Fellowship of the Ministry of Economy and Competitiveness of Spain (no. RYC-2013-13628). 
Open Access This article is distributed under the terms of the Creative Commons Attribution-NonCommercial 4.0 International License (http://creativecommons.org/licenses/by-nc/4.0/), which permits any noncommercial use, distribution, and reproduction in any medium, provided you give appropriate credit to the original author(s) and the source, provide a link to the Creative Commons license, and indicate if changes were made.

\section{References}

Abrahamson V, Wolf J, Lorenzoni I, Fenn B, Kovats S, Willkinson P, Adger WN, Raine R (2008) Perceptions of heatwave risks to health: interview-based study of older people in London and Norwich, UK. J Public Health 31(1):119-126. https://doi.org/10.1093/pubmed/fdn102

Ackerman F, Heinzerling L (2004) Priceless: on knowing the price of everything and the value of nothing. The New Press, New York

Anderson GB, Bell ML (2011) Heat waves in the United States: mortality risk during heat waves and effect modification by heat wave characteristics in 43 U.S. communities. Environ Health Perspect 19(2):210-218

Armstrong B, Gasparrini A, Hajat S (2014) Estimating mortality displacement during and after heat waves. Am J Epidemiol 79(12):1405-1406. https://doi.org/10.1093/aje/kwu08

Åström DO, Tornevi A, Ebi KL, Rocklow J, Forsberg B (2016) Evolution of minimum mortality temperature in Stockholm, Sweden, 1901-2009. Environ Health Perspect 124(6):740-744. https://doi.org/10.1289 /ehp.1509692

Azhar GS, Mavalankar D, Nori-Sarma A, Rajiva A, Dutta P, Jaiswal A, Sheffield P, Knowlton K, Hess JJ, on behalf of the Ahmedabad Heat Climate Study Group (2014) Heat-related mortality in India: excess all-cause mortality associated with the 2010 Ahmedabad heat wave. PLoS One 9(3):e91831. https://doi.org/10.1371 /journal.pone.0091831

Baccini M, Kosatsky T, Analitis A, Anderson HR, D'Ovidio M, Menne B, Michelozzi P, Biggeri A, the PHEWE Collaborative Group (2011) Impact of heat on mortality in 15 European cities: attributable deaths under different weather scenarios. J Epidemiol Community Health 65(1):64-67. https://doi.org/10.1136 /jech.2008.085639

Beniston M (2004) The 2003 heat wave in Europe: a shape of things to come? An analysis based on Swiss climatological data and model simulations. Geophys Res Lett 31(2). https://doi.org/10.1029/2003GL018857

Benmarhnia T, Sottile MF, Plante C, Brand A, Casati B, Fournier M, Smargiassi A (2014) Variability in temperature-related mortality projections under climate change. Environ Health Perspect 122:1293-1298. https://doi.org/10.1289/ehp.1306954

Benmarhnia T, Bailey Z, Kaiser D, Auger N, King N, Kaufman JS (2016) A difference-in-differences approach to assess the effect of a heat action plan on heat-related mortality, and differences in effectiveness according to sex, age, and socioeconomic status (Montreal, Quebec). Environ Health Perspect 124(11):1694-1699. https://doi.org/10.1289/EHP203

Bickel P, Friedrich R (2005) Externalities of energy, methodology 2005 update. European Commission, Luxembourg, p 270

Chanel O (2011) Guidelines on monetary cost calculations related to air-pollution health impacts. Deliverable D6, APHEKOM project, Improving Knowledge and Communication for Decision Making on Air Pollution and Health in Europe

Chilton SM, Covey J, Jones-Lee M, Loomes G, Metcalf H (2004) Valuation of health benefits associated with reductions in air pollution: final report PB 9413. DEFRA, London

Christidis N, Jones GS, Stott PA (2014) Dramatically increasing chance of extremely hot summers since the 2003 European heatwave. Nat Clim Chang 5(1):46-50. https://doi.org/10.1038/nclimate2468

Colacino M, Conte M (1995) Heat waves in the Central Mediterranean. A Synoptic Climatol Il Nuovo Cimento 18(C):295-304. https://doi.org/10.1007/BF02508561

Comunidad de Madrid (2015) Vigilancia y control de los efectos de las olas de calor 2015. Plan de respuesta antes los riesgos; www.madrid.org, last access 11/10/2016

De Ayala A, Spadaro J (2014) Economic costs of health effects. Report on work package 10 (WP10) for PURGE FP7 project

Dessai S (2003) Heat stress and mortality in Lisbon part II. An assessment of the potential impacts of climate change. Int J Biometeorol 48(1):37-44. https://doi.org/10.1007/s00484-003-0180-4

Díaz J, Carmona R, Mirón IJ, Ortiz C, León I, Linares C (2015) Geographical variation in relative risks associated with heat: update of Spain's heat wave prevention plan. Environ Int 85:273-283. https://doi. org/10.1016/j.envint.2015.09.022 
Ebi KL, Teisberg TJ, Kalkstein LS, Robinson L, Weiher RF (2004) Heat watch/warning systems save lives: estimated costs and benefits for Philadelphia 1995-98. Bull Am Meteorol Soc 85(8):1067-1073. https://oi. org/10.1175/BAMS-85-8-1067

EPA (2015) Climate change in the United States: benefits of global action. US Environmental Protection Agency, Office of Atmospheric Programs (OAP), EPA 430-R-15-001

European Commission (1999) DGXII (JOULE Programme) externalities of energy, ExternE project, report 7 , methodology: update 1998. Holland, M.R. and Forster, D. (eds). http://www.externe.info/externe_d7/. Accessed January 31, 2018.

Fouillet A, Rey G, Wagner V, Laaidi K, Empereur-Bissonnet P, Le Tertre A, Frayssinet P, Bessemoulin P, Laurent F, De Crouy-Chanel P, Jougla E, Hémon D (2008) Has the impact of heat waves on mortality changed in France since the European heat wave of summer 2003? A study of the 2006 heat wave. Int J Epidemiol 37(2):309-317. https://doi.org/10.1093/ije/dym25

Gardner JW, Sanborn JS (1990) Years of potential life lost (YPLL) - what does it measure? Epidemiology 1(4): 322-329. https://doi.org/10.1097/00001648-199007000-00012

Gosling SN, Lowe JA, McGregor GR, Pelling M, Malamud BD (2009) Associations between elevated atmospheric temperature and human mortality: a critical review of the literature. Clim Chang 92(3-4): 299-341. https://doi.org/10.1007/s10584-008-9441-x

Hajat S, Armstrong BG, Gouveia N, Wilkinson P (2005) Mortality displacement of heat-related deaths. A comparison of Delhi, Sao Paulo and London. Epidemiology 16(5):613-620. https://doi.org/10.1097/01. ede.0000164559.41092.2a

Hunt A, Ferguson J, Baccini M, Watkiss P, Kendrovski V (2017). Climate and weather service provision: economic appraisal of adaptation to health impacts. Climate Service 7:78-86

Hurley F, Hunt A, Cowie H, Holland M, Miller B, Pye S, Watkiss P (2005) Methodology for the cost-benefit analysis for CAFE: volume 2: health impact assessment. AEA Technology Environment, UK. Report to DG Environment of the European Commission. AEAT/ED51014/Methodology Volume 2 Issue 1

Hutton G, Rehfuess E (2006) Guidelines for conducting cost-benefit analysis of household energy and health interventions. WHO 2006; ISBN 9241594810

Im ES, Pal JS, Eltahir EAB (2017) Deadly heat waves projected in the densely populated agricultural regions of South Asia. Sci Adv 3(8):e1603322. https://doi.org/10.1126/sciadv.1603322

INE (Instituto Nacional de Estadística, Spanish Statistical Office) (2014). http://www.ine. es/en/inebaseDYN/propob30278/propob_resultados_en.htm, last access 11/10/2016

IPCC (2014) Climate change 2014: synthesis report. contribution of Working Groups I, II and III to the fifth assessment report of the Intergovernmental Panel on Climate Change. Pachauri, R.K. and Meyer, L.A. (Eds.). IPCC, Geneva, Switzerland, pp. 151

Linares C, Díaz J (2008) Impact of high temperatures on hospital admissions: comparative analysis with previous studies about mortality (Madrid). Eur J Pub Health 18:318-322

Linares C, Carmona R, Díaz J (2014) Análisis del impacto a corto plazo de los extremos térmicos y de otros factores ambientales sobre la mortalidad diaria en la ciudad de Madrid en el periodo 2001-2009. Reports I and II prepared for the European Commission under the BASE (Bottom-up Climate Adaptation Strategies Towards a Sustainable Europe) Project, 7th Research Framework Programme

Linares C, Martínez-Martín P, Rodríguez-Blazquez C, Forjaz MJ, Carmona R, Díaz J (2016) Effect of heat wave on morbidity and mortality due to Parkinson's disease in Madrid: a time-series analysis. Environ Int 89-90: 1-6. https://doi.org/10.1016/j.envint.2016.01.017

Lindheim H, Navrud S, Braathen NA, Biausque V (2011) Valuing mortality risk reductions from environmental, transport and health policies: a global meta-analysis of stated preference studies. Risk Anal 31(9):13811407. https://doi.org/10.1111/j.1539-6924.2011.01694.x

Martinez Austria PF, Bandala ER (2016) Maximum temperatures and heat waves in Mexicali, Mexico: trends and threshold analysis. Air, Soil and Water Res 9:21-28

McDonnell S, Vossberg K, Hopkins RS, Mittan B (1998) Using YPLL in health planning. Public Health Rep 113(1):55-61

McGregor GR, Bessemoulin P, Ebi KL, Menne B (2015) Heatwaves and health: guidance on warning-system development. World Meteorological Organization and World Health Organization, Geneva, Switzerland. WMO-No 1142

Menne B, Matthies F (2009) Improving public health responses to extreme weather/heat-waves-EuroHEAT, Technical Summary, WHO 2009

Meusel D, Menne B, Kirch W, Bertollini R (2004) Public health responses to extreme weather and climate events. A brief summary of the WHO meeting on this topic in Bratislava on 9-10 February 2004. J Public Health 12(6):371-381. https://doi.org/10.1007/s10389-004-0068-8 
O’Neill BC, Kriegler E, Riahl K, Ebi KL, Hallegatte S, Carter TR, Mathur R, van Vuuren D (2013) A new scenario framework for climate change research: the concept of shared socio-economic pathways. Clim Chang 122(3):387-400. https://doi.org/10.1007/s10584-013-0905-2

O’Neill BC, Kriegler E, Riahl K, Ebi KL, Kemp-Benedict E, Riahi K, Rothman DS, van Ruijven BJ, van Vuuren DP, Birkmann J, Kok K, Levy M, Solecki W (2015) The roads ahead: narratives for shared socioeconomic pathways describing world futures in the 21st century. Global Environmental Change, available online 12 February 2015; https://doi.org/10.1016/j.gloenvcha.2015.01.004

OECD (2001) OECD health data 2001: a comparative analysis of 30 countries. OECD, Paris

OECD (2008) Valuing lives saved from environmental, transport and health policies: a meta-analysis of stated preference studies. OECD, Paris, ENV/EPOC/WPNEP (2008)10

OECD (2011) Valuing mortality risk reductions in regulatory analysis of environmental, health and transport policies: policy implications. OECD, Paris

ONERC (2009) Climate change: costs of impacts and lines of adaptation, Observatoire National sur les Effets du Réchauffement Climatique (National Observatory for the Impacts of Global Warming). Report to the Prime Minister and Parliament

Patokos T (2010) Lives in the hands of economists: a critical review of the main methodologies used to derive the value of a statistical life. Environ Econ 1(2):8-17

PHE (Public Health England) (2013) Heat wave plan for England 2013. Available at https://www.gov. uk/government/, last access 2/9/2016

Rogers DP, Shapiro MA, Brunet G, Cohen J-C, Connor SJ, Diallo AA, Elliot W, Haidong K, Hales S, Hemming D, Jeanne I, Lafaye M, Mumba Z, Raholijao N, Rakotomanana F, Teka H, Trtanj J, Whung P-Y (2010) Health and climate-opportunities. Procedia Environ Sci 1:37-54. https://doi.org/10.1016/j. proenv.2010.09.005

Saha MV, Davis RE, Hondula DM (2014) Mortality displacement as a function of heat event strength in 7 US cities. Am J Epidemiol 179(4):467-474. https://doi.org/10.1093/aje/kwt264

Scoccimarro E, Gualdi S (2014) High-resolution climate data over Europe for the Bottom-up Climate Adaptation Strategies towards a Sustainable Europe (BASE) project. Technical report for the FP-7 base project, Centro Euro-Mediterraneo sui Cambiamenti Climatici (CMCC), Bologna, Italy

Seifert LI, Weithoff G, Vos M (2015) Extreme heat changes post-heat wave community reassembly. Ecol Evol 5(11):2140-2148. https://doi.org/10.1002/ece3.1490

Van Vuuren DP, van Kriegler E, O’Neill BC, Ebi KL, Riahi K, Carter TR, Edmonds J, Hallegatte S, Kram T, Mathur R, Winkler H (2014) A new scenario framework for climate change research: scenario matrix architecture. Clim Chang 122(3):373-386. https://doi.org/10.1007/s10584-013-0906-1

Vardoulakis S, Dear K, Hajat S, Heaviside C, Eggen B, McMichael AJ (2014) Comparative assessment of the effects of climate change on heat- and cold-related mortality in the United Kingdom and Australia. Environ Health Perspect 122:1285-1292. https://doi.org/10.1289/ehp.1307524

Wang L, Huang J, Luo Y, Yao Y, Zhao Z (2015) Changes in extremely hot summers over the global land area under various warming targets. PLoS One 10(6):e0130660. https://doi.org/10.1371/journal.pone.0130660

Watkiss P, Pye S, Holland M (2005) CAFE (Clean Air for Europe) CBA: baseline analysis 2000 to 2020. Report to the European Commission DG Environment, Brussels

WHO (2013) WHO methods and data sources for global burden of disease estimates 2000-2011. Global Health Estimates Technical Paper WHO/HIS/HSI/GHE/2013.4. Department of Health Statistics and Information Systems. WHO, Geneva

Zuo J, Pullen S, Palmer J, Bennetts H, Chileshe N, Ma T (2015) Impacts of heat waves and corresponding measures: a review. J Clean Prod 92:1-12. https://doi.org/10.1016/j.jclepro.2014.12.078 